\title{
ANALISIS POTENSI PASAR IKAN KERAPU DI PULAU BONETAMBU KECAMATAN UJUNG TANAH KELURAHAN BARRANG CADDI KOTA MAKASSAR
}

\section{Analysis Market Potential Of Grouper In Bonetambu Island Ujung Tanah Subdistrict Barrang Caddi Village Makassar City}

Karina Arfany Arfah, Tenaga Pengajar Pada IISIP Yapis Biak(Papua)

\begin{abstract}
Abstrak
Penelitian ini bertujuan untuk mengetahui Berapa Besar Potensi Pasar dan Ikan Kerapu Di Pulau Bonetambu Kecamatan Ujung Tanah Kelurahan Barrang Caddi Kota Makassar. Penelitian ini dilaksanakan di Pulau Bonetambu.Penentuan lokasi dilakukan secara sengaja dan waktu penelitian dilaksanakan pada bulan Januari sampai Februari 2012. Data yang digunakan adalah data primer dan sekunder. Data primer tersebut diperoleh dari hasil observasi dan wawancara dengan responden sedangkan data sekunder diperoleh dari kantor kelurahan Barrang Caddi. Metode pengumpulan sampel dilakukan secara berkelompok dengan jumlah sampel sebanyak 17 orang nelayan, 5 orang pedagang pengumpul dan 23 orang konsumen rumah tangga. Sehingga total sampel keseluruhan adalah 45 orang. Hasil penelitian ini menunjukkan bahwa berdasarkan permintaan konsumen, pedagang pengumpul dan eksportir ikan kerapu memiliki potensi pasar yang besar. Dari tiga komoditas ikan kerapu (Sunu, Lumpur dan Macan) ukuran > 1 kg yang memiliki potensi pasar yang besar. Untuk kerapu hidup yang memiliki potensi pasar terbesar adalah kerapu sunu (Plectopormus leopardus) sedangkan kerapu mati yang memiliki potensi pasar yang besar adalah kerapu lumpur (Epinephelus coloides).
\end{abstract}

Kata kunci: Potensi pasar, Ikan kerapu Sunu, Lumpur dan Macan.

\section{Pendahuluan}

Indonesia adalah negara kepulauan terbesar didunia karena memiliki luas laut dan jumlah pulauyang besar. Panjang garis pantai Indonesia mencapai $104.000 \mathrm{~km}$ dengan luas wilayah laut mendominasi total luas territorial Indonesia sebesar 7,7 juta $\mathrm{km}^{2}$. Potensi tersebut menempatkan Indonesia sebagai negara yang dikaruniai sumberdaya kelautan yang besar termasuk kekayaankeanekaragaman hayati dan non hayati kelautan terbesar (Badan Koordinasi Survei dan Pemetaan Nasional, 2006).

Potensi perikanan tangkap di Sulawesi Selatan dimana usaha perikanan tangkap di Sulawesi Selatan dilaksanakan di laut dan perairan umum. Pada usaha perikanan tangkap di laut komoditi hasil tangkapannya yaitu kerapu yang sangat menonjol dan bernilai ekonomis tinggi. Ikan kerapu merupakan salah satu jenis perikanan laut domersal yang populer di pasaran internasional dengan namagrouper atau trout. Harga ikan kerapu hidup sangat mahal, tergantung jenisnya. Jenis-jenis kerapu yang diekspor adalah kerapu alis, kerapu macan, kerapu minyak, kerapu lodi, kerapu lumpur, kerapu sunu dan kerapu karet (Murtidjo, 2002).

Ekspor ikan kerapu melaju pesat, dari 19 ton padatahun 1987 menjadi 57 ton pada tahun 1988 (Deptan, 1990). lkan kerapu (Epinephelus spp) merupakan jenis ikan ekonomis penting yang disukai orang khususnya etnis keturunan China. Terdapat lima negara utama pemasok ikan kerapu 
Jurnal "Gema Kampus" Edisi Vol.12 No.2 Tahun 2017

hidup untuk Hongkong, Indonesia memegang 20\% pangsa pasar Hongkong, menempati urutan kedua setelah Thailand. Hasil survei Ditjen Perikanan tercatat 20 jenis kerapu dengan 12 jenis merupakan kerapu komersial. Daerah penangkapan ikan kerapu meliputi hampir semua perairan karang yang ada di Indonesia. Penangkapan ikan telah mencapai perairan karang yang jauh dari pemukirnan penduduk. Karena keuntungan yang diperoleh dalam perdagangan kerapu hidup sangat tinggi, rnaka ikan kerapu banyak diburu orang.

Ikan kerapu hidup merupakan komoditas ekspor Indonesia dengan daerah tujuan ekspor utama Hongkong. Agriculture and Fisheries Department(AFD) Hongkong memperkirakan konsumsi ikan kerapu hidup Hongkong antara 5.000 - $6000 \mathrm{mt}$.

Nilai jual ikan dalam kondisi hidup jauh lebih tinggi dari ikan dalam keadaan mati (segar). Sebagai contoh harga ekspor per $\mathrm{kg}$ untuk jenis kerapu Bebek (Chromileptis altivelis) kondisi hidup mencapai US\$ 40 50 , sedang untuk kondisi mati (segar) US\$ 10 - 15. Harga kerapu Bebek hidup di tingkat produsen atau pembudidaya jaring apung dapat mencapai Rp 350.000, kerapu Macan Rp 90.000 per kg. Oleh karena itu penanganan pasca panen ikan kerapu hidup berperan sangat penting.Ikan kerapu menjadi salah satu ikan laut bernilai jual tinggi.

Pulau Bonetambu merupakan salah satu pulau dalam gugusan pulau atau kepulauan Spermonde, Sulawesi Selatan. Secara administratif termasuk ke dalam wilayah Kecamatan Ujung Tanah, Kelurahan Barrang Caddi, Kota Makassar. Pulau Bonetambu berbentuk bulat dan memiliki luas 2,8 Ha dengan panjang garis pantai mencapai $700 \mathrm{~m}$. Masyarakat pulau Bonetambu sebagian besar memiliki profesi sebagai nelayan melihat daerah ini dikelilingi oleh lautan, nelayan Pulau Bonetambu umumnya menangkap gurita dengan menggunakan pancing dan sebagian menangkap ikan dengan menggunakan bubu, beberapa diantaranya menangkap ikan kerapu, katambak, levis, dan beberapa jenis ikan karang lainnya.

Kendala-kendala dan permasalahan yang ada di Pulau Bonetambu yaitu masih banyaknya nelayan Bonetambu yang kurang dalam hal pengetahuan tentang informasi pasar, dimana menyangkut harga yang sedang bersaing di pasar terkait komoditas yang ditangkap, baik pasar domestik maupun internasional dan juga terkendala dalam permodalan.

Adanya potensi pasar yang cukup besar, serta tingginya minat masyarakat terhadap permintaan ikan kerapu. Sehingga dengan melihat permasalahan yang cukup konkrit dan tuntutan peluang pasar yang memerlukan solusi secara cepat, maka perlu dilakukan penelitian tentang "Analisis Pootensi Pasar Ikan Kerapu Di Pulau Bonetambu Kecamatan Ujung Tanah Kelurahan Barrang Caddi Kota Makassar".

\section{Metode Penelitian}

\section{A. Waktu dan Tempat}

Penelitian ini dilaksanakan pada bulan Januari - Februari 2012, bertempat di Pulau Bonetambu, Kecamatan Ujung Tanah, Kelurahan Barrang Caddi, Kota Makassar. Pemilihan lokasi penelitian dilakukan secara sengaja (Purposive) yang didasari pada pertimbangan bahwa Pulau Bonetambu merupakan salah satu Pulau yang mayoritas nelayannya adalah nelayan tangkap bubu dengan hasil tangkapan ikan kerapu, disamping itu letaknya tidak jauh dari Kota Makassar.

\section{B. Jenis dan Metode Penelitian}

Jenis penelitian ini adalah penelitian kuantitatif yang akan menjelaskan besarnya 
Karina Arfany Arfah "Analisis Potensi Pasar Ikan Kerapu di Pulau Bonetambu Kecamatan Ujung Tanah Kelurahan Barrang Caddi Kota Makassar"

peluang pasar dari ikan kerapu, dimana metode pengambilan data yang dilakukan oleh peneliti di lokasi penelitian yang telah ditentukan secara langsung dalam rangka pengumpulan data yang diperlukan. Data yang didapatkan dari lapangan diolah sesuai dengan analisis yang digunakan.

Metode yang digunakan dalam penelitian ini adalah metode penelitian survei yaitu observasi lapangan dan wawancara langsung dengan responden yang terpilih dengan menggunakan kuisioner sebagai alat pengumpul data.

\section{Populasi dan Pengambilan Sampel}

Populasi dalam penelitian ini adalah semua nelayan, pedagang pengumpul ikan kerapu yang ada di Pulau Bonetambu dan konsumen rumah tangga. Penentuan sampel pada penelitian ini dilakukan secara pengelompokan (cluster random sampling) yaitu suatu metode pengambilan sampel dengan mengklasifikasikan sampel secara sederhana, banyaknya populasi dan sampel dari masing-masing responden dapat dilihat pada tabel berikut ini :

\begin{tabular}{c|l|c|c|c}
\hline No & \multicolumn{1}{|c|}{ Responden } & Populasi (Orang) & Sampel (Orang) & Persentase(\%) \\
\hline 1. & Nelayan & 115 & 17 & 15 \\
\hline 2. & Pedagang Pengumpul & 5 & 5 & 100 \\
\hline 3. & Konsumen RT & 150 & 23 & 15 \\
\hline & Jumlah & $\mathbf{2 7 0}$ & $\mathbf{4 5}$ & \\
\hline
\end{tabular}

Tabel 1. Jumlah populasi dan sampel pada masing-masing responden

Hal ini sesuai dengan pendapat Prasetiyo (2005) yang menyatakan bahwa jika jumlah sampel kurang dari 100 maka lebih baik diambil semua, tetapi jika jumlah sampel lebih dari 100 maka dapat diambil antara 10$15 \%$ dari jumlah populasi ataupun tergantung dari kemampuan peneliti, luas wilayah dan besar kecilnya resiko yang ditanggung peneliti.

\section{Teknik Pengambilan Data}

Data dari hasil penelitian ini dapat diperoleh dengan cara sebagai berikut :

1. Observasi lapangan berupa pengamatan secara langsung terhadap berbagai aktivitas keseharian nelayan Ikan Kerapu yang berkaitan dengan penelitian yang dilaksanakan.

2. Wawancara secara langsung dengan dengan para nelayan Ikan Kerapu dan menggunakan kuisioner sebagai alat bantu untuk membicarakan berbagai hal yang berhubungan dengan penelitian yang dilaksanakan.

3. Studi Pustaka yang dapat berupa pengambilan data melalui literatur atau hasil-hasil penelitian terdahulu yang relevan dengan tema penelitian.

\section{E. Sumber data}

Data yang dikumpulkan dalam penelitian ini dapat bersumber dari :

1. Data Primer, yaitu data yang diperoleh secara langsung di lapangan dengan cara observasi, pengisian kuisioner dan wawancara langsung dengan responden yaitu nelayan, pedagang pengumpul dan konsumen akhir ikan kerapu yang dapat memberikan informasi yang berkaitan dengan data yang dikumpulkan.

2. Data Sekunder, yaitu data yang diperoleh dari berbagai sumber atau instansi terkait seperti Dinas Kelautan dan Perikanan, 
Biro Pusat Statistik dan instansi terkait lainnya.

\section{F. Analisis Data}

Data dari informasi yang diperoleh akan dianalisa untuk mengetahui berapa besar potensi pasar Ikan Kerapu, maka dapat digunakan rumus sebagai berikut (Kotler, 1999) :

$$
\mathrm{Q}=n \times q \times p
$$

Dimana :

$$
\begin{aligned}
& \mathrm{Q}=\text { Potensi pasar total ikan kerapu } \\
& n=\text { Jumlah konsumen ikan kerapu } \\
& q=\text { Jumlah ikan kerapu yang dibeli } \\
& \text { oleh rata-rata konsumen } \\
& p=\text { Harga untuk setiap kg ikan kerapu }
\end{aligned}
$$

\section{Hasil dan Pembahasan}

\section{A. Usaha Penangkapan Ikan Kerapu}

Bubu adalah alat tangkap yang umum dikenal dikalangan nelayan, yang berupa jebakan, dan bersifat pasif. Bubu sering juga disebut perangkap " traps " dan penghadang "guiding barriers". Di samping itu juga penggunaan alat tangkap ini secara balk dan benar akan sangat mendukung Code of conduct for responsible fishing, yaitu pengembangan perikanan tradisional dengan penggunaan alat tangkap yangselektif dan memperkecil hasil tangkapan non target (Monintja dan Bahrudin, 1996). Alat tangkap bubu mempunyai spesifikasi khas sesuai dengan kondisi laut dimana dilakukan penangkapan. Pengoperasian bubu di laut dalam sering dilakukan dengan berbagai macam cara untuk menarik perhatian ikan misalnya dengan meletakkan umpan atau membuat bubu semenarik mungkin .

\section{Deskripsi Alat Tangkap Bubu}

Nelayan Pulau Bonetambu umumnya memiliki alat tangkap jenis bubu dengan perahu motor berkekuatan 22-24 PK, dan mesin Kompressor 5 PK. Pada prinsipnya alat perangkap bubu ikan adalah merupakan alat tangkap yang ukurannya kecil. Jenis alat tangkap bubu dapat di lihat pada gambar di bawah ini :

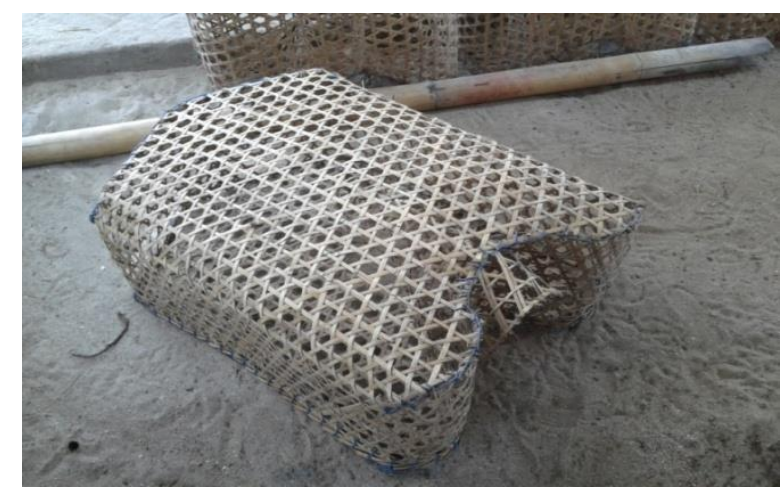

Sumber : Dok. Lapangan, 2012

\section{Gambar 1. Alat perangkap bubu ikan}

Bubu dasar (Ground Fish Pots) yang digunakan nelayan Pulau Bonetambu pada operasi penangkapan terbagi atas 3 bagian yaitu :

a. Badan atau tubuh bubu.

Badan atau tubuh bubu terbuat dari anyaman bambu berbentuk persegi panjang dengan ukuran yaitu panjang $125 \mathrm{~cm}$, lebar $80 \mathrm{~cm}$, tinggi $40 \mathrm{~cm}$. Pada bagian badan atau tubuh bubu ini tidak dilengkapi pemberat seperti yang dilakukan nelayan pada umumnya tapi pemberat pada bubu diambil dari karang tempat dimana bubu dipasang pada dasar laut.

b. Lubang tempat mengeluarkan hasil tangkapan.

Lubang tempat mengeluarkan hasil tangkapan terletak pada sisi bagian bawah bubu. Lubang ini berdiameter $35 \mathrm{~cm}$, posisinya tepat berada di belakang mulut bubu dan lubang ini dilengkapi dengan penutup.

c. Mulut bubu.

Mulut bubu berfungsi untuk tempat masuknya ikan yang terletak pada bagian depan badan bubu. Posisi mulut bubu menjorok ke dalam badan atau tubuh bubu, berbentuk silinder. Dari luar ke dalam 

Kelurahan Barrang Caddi Kota Makassar"

semakin mengecil yaitu ukuran mulut luar (diameter terbesar $45 \mathrm{~cm}$, terkecil $25 \mathrm{~cm}$ ), ukuran mulut dalam (diameter terbesar 20 $\mathrm{cm}$, terkecil $10 \mathrm{~cm}$ ) dan mesh size (ukuran lubang kecil pada bubu) yaitu $5 \mathrm{~cm}$. Pada bagian mulut dalam melengkung ke bawah sepanjang $15 \mathrm{~cm}$. Lengkungan ini berfungsi agar ikan yang masuk tidak dapat meloloskan diri keluar atau dapat tertangkap sampai pada saat pengambilan hasil tangkapan.

\section{Tahap Persiapan Penangkapan}

Dalam operasi penangkapan alat perangkap bubu ikan yang dilakukan oleh nelayan Pulau Bonetambu dibutuhkan beberapa perlengkapan yaitu :

Tabel 2. Alat bantu dalam operasi penangkapan ikan kerapu

\begin{tabular}{l|l|l}
\hline No. & Alat Bantu Penangkapan & \multicolumn{1}{|c}{ Jumlah } \\
\hline 1 & Perahu & 1 unit \\
\hline 2 & Bubu & 8 buah \\
\hline 3 & Umpan & 2 keranjang \\
\hline 4 & Pelampung Tanda & 4 buah \\
\hline 5 & Keranjang/ basket & 2 buah \\
\hline 6 & Coolbox & 2 buah \\
\hline 7 & Jarum Suntik & 1 buah \\
\hline 8 & Sarung Tangan & 5 pasang \\
\hline 10 & Pemberat & 2 buah \\
\hline 11 & Mins & 2 pasang \\
\hline 12 & Kacamata snorkel & 2 buah \\
\hline 13 & Kantongan plastik & 8 buah \\
\hline 14 & Mesin kompresor & 1 buah \\
\hline 15 & Bak penampungan & 1 buah \\
\hline
\end{tabular}

Sumber : Data Primer setelah diolah,2012

\section{Metode Pengoperasian Alat Tangkap}

Alat tangkap yang digunakan di Pulau Bonetambu untuk menangkap ikan kerapu yaitu alat perangkap bubu dasar (Ground Fish Pots) dimana daerah operasionalnya berada di dasar perairan. Adapun cara pengoperasiannya setelah menentukan lokasi penangkapan (fishing ground) yaitu nelayan mempersiapkan alat perangkap bubu yang akan di turunkan dengan cara mengikatkan tali pelampung penanda lokasi pada kedua ujung alat tangkap bubu, dimana 2 alat perangkap bubu ikan di ikat dengan 1 pelampung penanda lokasi. Dalam melakukan penurunan atau pemasangan alat perangkap bubu nelayan terlebih dahulu memakai baju yang biasa digunakan untuk menyelam dan menggunakan pemberat yang diikat dipinggang sebagai pemberat untuk mempermudah ketika turun kedasar laut.Kemudian dibantu dengan kompresor yang telah dilengkapi selang yang telah dilengkapi regulator selam sebagai pengganti scuba untuk membantu pernapasan ketika menyelam kedasar laut.

Alat perangkap bubu kemudian diturunkan beserta umpan yang telah dipegang oleh penyelam. Pelampung penanda lokasi kemudian dikaitkan ke bagian perahu agar tidak lepas ketika alat diturunkan. Setelah pelampung penanda lokasi dikaitkan, salah satu nelayan membantu menurunkan selang kompresor secara perlahan-lahan agar selang tidak saling terbelit sehingga memperlancar saluran udara yang mengalir dari tabung kompresor ke regulator selam.Ketika alat perangkap bubu ikan sudah berada di dasar perairan, nelayan kemudian melepas tali pelampung tanda dan mengikatkannya pada salah satu karang yang dianggap cukup kuat menahan arus air laut.Terkadang hal ini tergantung dari kemauan nelayan jika ingin mengikatkannya pada karang atau tetap mengikatkannya pada salah satu alat perangkap bubu ikan. Kemudian nelayan menentukan kembali lokasi dimana bubu akan disimpan.

Setelah lokasi penyimpanan ditentukan nelayan, kemudian alat perangkap bubu ikan diberi pemberat pada bagian atasnya dengan menggunakan terumbu karang yang ada disekitar lokasi alat tangkap di simpan. Fungsi karang juga digunakan untuk menghias alat tangkap dengan cara meletakkan karang dikedua sisi samping alat tangkap bubu dan bagian belakang tapi tidak 
pada bagian depan karena bagian depan adalah pintu masuk ikan. Tujuan menghias alat perangkap bubu ikan yaitu untuk memanipulasi atau mengecoh ikan agar alat tangkap tidak terlalu tampak.Hal ini juga di lakukan pada alat perangkap bubu ikan lainnya.

Setelah alat tangkap telah selesai disimpan, penyelam kemudian menarik tali kompresor sebagai tanda kalau alat telah selesai disimpan.Nelayan yang berada di atas perahu kemudian membantu menarik selang kompresor untuk membantu penyelam berenang ke permukaan perairan. Hal yang sama dilakukan dengan alat perangkap bubu ikan lainnya.

Setelah semua alat tangkap diturunkan, maka alat tangkap dibiarkan selama \pm 2 jam berada didasar perairan. Setelah alat perangkap bubu ikan sudah cukup lama berada di dasar perairan maka tahapan selanjutnya yaitu penarikan alat perangkap bubu ikan. Dalam melakukan penarikan alat perangkap bubu ikan hal yang harus diperhatikan adalah tempat dimana posisi pelampung tanda disimpan, karena sebagian besar nelayan alat perangkap bubu ikan beroperasi di wilayah perairan yang sama.

Hal pertama yang dilakukan yaitu menarik pelampung tanda yang kemudian dikaitkan dibagian badan kapal agar tidak lepas. Kemudian penyelam turun mengikuti tali pelampung yang telah diikat dikarang di dasar perairan dengan bantuan alat kompresor yang telah di sambung dengan selang dan regulator sebagai alat bantu napas selama berada di air. Setelah penyelam berada di dasar perairan, tali pelampung kemudian diikatkan pada alat perangkap bubu ikan pada bagian pintu masuk ikan.Hal ini dilakukan agar pada saat dilakukannya penarikan alat dari nelayan yang berada di atas kapal, ikan tidak dapat keluar karena posisi pintu masuk menghadap ke atas.Hal ini juga yang membedakan posisi ikatan tali pelampung tanda ketika alat perangkap bubu ikan diturunkan dan ketika alat perangkap bubu ikan dinaikkan.Setelah penyelam telah selesai mengikat tali pelampung tanda pada alat perangkap bubu ikan, kemudian penyelam menarik tali sebagai tanda kalau alat perangkap bubu ikan siap untuk ditarik naik ke atas.Setelah alat perangkap bubu ikan sudah berada di atas kapal maka nelayan yang berada di atas kemudian memegang selang kompresor untuk menunggu tanda penyelam menarik selang kompresor sebagai tanda alat perangkap bubu ikan yang kedua siap untuk dinaikkan.

Dalam hal ini alat perangkap bubu ikan yang kedua dipegang sendiri oleh penyelam dan biasa hanya dijepit diantara kedua kaki.Kemudian penyelam tinggal menunggu selang kompresor ditarik untuk membantu penyelam naik ke atas.Setelah penyelam telah naik di atas kapal beserta alat perangkap bubu ikan yang dibawanya maka kegiatan selanjutnya yaitu penanganan hasil tangkapan.

\section{B. Daerah Operasi, Waktu dan Musim Penangkapan}

Nelayan bubu mempunyai daerah penangkapan di sekitar Pulau Lanjukkang, Pulau Sabaru di perairan Pangkep, Pulau Pammantauang (taka 7 dan taka 6), Pulau Jangang-jangang, dan Pulau Tombakulu. Daerah penangkapan ini terletak \pm 60 mil dari Pulau Bonetambu dengan menempuh perjalanan selama kurang lebih 2 jam. Nelayan bubu di Pulau ini melaut 2 kali dalam seminggu pertripnya selama tiga hari yaitu hari sabtu-senin, selasa-kamis (tergantung musim), nelayan tidak melaut pada hari jum'at.

Pengoperasian alat tangkap bubu di Pulau Bonetambu dilakukan satu trip selama tiga hari (tergantung musim). Nelayan berangkat pada pukul 05.00 pagi dan kembali 

Kelurahan Barrang Caddi Kota Makassar"

pada pukul 14.00, kemudian nelayan menjual tangkapannya langsung ke pedagang pengumpul di Pulau Bonetambu dan pada pukul 14.30 nelayan menuju Makassar untuk menjual ikan kerapu hidup.

Musim penangkapan dibagi atas musim timur, barat dan sedang. Pada musim timur (puncak) yang dimulai pada bulan Agustus - Desember, musim barat (paceklik) yang dimulai pada bulan Januari-April dan musim sedang dimulai pada bulan MeiJuli.Curah hujan pada musim barat cukup tinggi, sementara untuk musim timur curah hujannya relatif lebih rendah dan gelombang laut cukup tenang sehingga frekwensi nelayan untuk melaut lebih tinggi. Aktivitas nelayan untuk melaut pada musim timur biasanya sebanyak 20-26 trip/bulan yang berdampak pada tingginya hasil tangkapan, untuk musim barat karena kondisi cuaca yang kurang baik hanya memungkinkan nelayan melaut sebanyak 7-10 trip/bulan, sedangkan untuk musim sedang sebanyak 15-20 trip/bulan.

\section{Penanganan Hasil Tangkapan}

Dalam kegiatan penanganan hasil tangkapan hal yang diperhatikan yaitu pemisahan tempat ikan kerapu hidup dan segar. Untuk ikan hidup dalam hal ini ikan sunu (Plectropomusleopardus), kerapu lumpur (Epinephelus coloides) dan kerapu macan (Epinephelus fuscoguttatus) tempat penampungannya berupa bak yang kecil berukuran berkisar $1 \mathrm{x} 1$ meter yang berisi air laut. Dibagian dasar bak penampungan terdapat 4 lubang yang berfungsi sebagai tempat keluar masuknya air secara langsung dari laut. Ikan yang tertangkap kemudian disuntikkan jarum tepat digelembung renangnya untuk mengeluarkan sebagian udara akibat adanya perbedaan tekanan saat ikan berada didasar perairan yang kemudian naik ke atas saat ditangkap. Hal ini dilakukan agar ikan berenang normal dibak penampungan. Sedangkan untuk ikan kerapu segar tempat penampungannya hanya berupa keranjang penampungan yang kemudian nanti dimasukkan kedalam coolbox berisi es balok.

Setelah semua kegiatan penangkapan dilakukan maka hal yang dilakukan selanjutnya yaitu kembali ke fishing base.dan setelah kembali ke fishing base maka ikan hasil tangkapan langsung dijual. Ikan kerapu hidup dijual ke penampung ikan hidup dan kerapu mati/segar dijual ke pengumpul ikan yang kegiatannya menampung ikan hasil tangkapan mati yang kemudian dijual kembali.

\section{Potensi Pasar Ikan Kerapu}

Potensi pasar adalah ukuran suatu pasar yang menggambarkan permintaan tertinggi dari sekumpulan konsumen yang memiliki minat tertentu terhadap penawaran pasar tertentu. Jenis ikan kerapu yang ditangkap oleh nelayan Pulau Bonetambu terdiri dari tiga jenis sebagai berikut :

Tabel 3. Jenis ikan kerapu yang ditangkap oleh nelayan Pulau Bonetambu

\begin{tabular}{c|l|l}
\hline No & \multicolumn{1}{|c|}{ Jenis Ikan } & Nama Latin \\
\hline I & $\begin{array}{l}\text { Kerapu Sunu } \\
\text { (Coral trout })\end{array}$ & $\begin{array}{l}\text { Plectopormus } \\
\text { leopardus }\end{array}$ \\
\hline II & $\begin{array}{l}\text { Kerapu Lumpur } \\
\text { (Estuary } \\
\text { Grouper })\end{array}$ & $\begin{array}{l}\text { Epinephelus } \\
\text { coloides }\end{array}$ \\
\hline III & $\begin{array}{l}\text { Kerapu Macan } \\
\text { (Carpet cod })\end{array}$ & $\begin{array}{l}\text { Epinephelus } \\
\text { fuscoguttatus }\end{array}$ \\
\hline
\end{tabular}

Sumber : Data Primer setelah diolah,2012

Dari tabel 3 dapat dilihat bahwa terdapat tiga jenis ikan kerapu hasil tangkapan nelayan Pulau Bonetambu baik kerapu hidup maupun kerapu mati, jenisnya yaitu kerapu sunu (Coral trout), kerapu lumpur (Estuary Grouper ) dan kerapu macan (Carpet cod). 
Jumlah ikan kerapu hidup yang ditangkap nelayan dan harga jual untuk pedagang pengumpul ikan berdasarkan jenis tersebut dapat dilihat pada tabel berikut ini :

Tabel 4. Harga jual nelayan untuk pedagang ikan kerapu hidup

\begin{tabular}{c|c|c|c|c|c}
\hline \multirow{2}{*}{ Jenis } & \multirow{2}{*}{$\begin{array}{c}\text { Jumlah Yg } \\
\text { Ditangkap/trip }\end{array}$} & \multicolumn{4}{|c}{ Harga (Rp) } \\
\cline { 4 - 6 } & & $\begin{array}{c}\mathbf{0 , 1}- \\
\mathbf{0 , 2} \mathbf{~ k g}\end{array}$ & $\begin{array}{c}\mathbf{0 , 3}- \\
\mathbf{0 , 4} \mathbf{~ k g}\end{array}$ & $\begin{array}{c}\mathbf{0 , 5}-1 \\
\mathbf{K g}\end{array}$ & $>\mathbf{1 ~ K g}$ \\
\hline I & 24 & 2.000 & 4.000 & 6.000 & 10.000 \\
\hline II & 70 & 2.000 & 4.000 & 6.000 & 10.000 \\
\hline III & 46 & 2.000 & 4.000 & 6.000 & 10.000 \\
\hline Jumlah & $\mathbf{1 4 0}$ & $\mathbf{6 . 0 0 0}$ & $\mathbf{1 2 . 0 0 0}$ & $\mathbf{1 8 . 0 0 0}$ & $\mathbf{3 0 . 0 0 0}$ \\
\hline $\begin{array}{c}\text { RATA- } \\
\text { RATA }\end{array}$ & $\mathbf{4 6 . 6 7}$ & $\mathbf{2 . 0 0 0}$ & $\mathbf{4 . 0 0 0}$ & $\mathbf{6 . 0 0 0}$ & $\mathbf{1 0 . 0 0 0}$ \\
\hline
\end{tabular}

Sumber : Data Primer setelah diolah,2012

Dari tabel 4 dapat dilihat bahwa jumlah hasil tangkapan nelayan pertrip yang terbesar yaitu ikan jenis I (kerapu sunu) dan terkecil yaitu jenis II (kerapu lumpur), Sedangkan harga jual nelayan untuk pedagang pengumpul ikan kerapu hidup yang tertinggi yaitu kerapu sunu yang ukuran $>1$ kg sebesar Rp. 360.000, yang terendah yaitu ukuran 0,1-0,2 kg pada ikan kerapu lumpur dan macan sebesar Rp. 3.000.

Jumlah ikan kerapu mati yang ditangkap nelayan dan harga jual untuk pedagang pengumpul ikan berdasarkan jenis tersebut dapat dilihat pada tabel berikut ini: Tabel 5. Harga jual nelayan untuk pedagang ikan kerapu mati

Sumber : Data Primer setelah diolah, 2012

\begin{tabular}{|c|c|c|c|c|c|}
\hline \multirow{2}{*}{ Jenis } & \multirow{2}{*}{$\begin{array}{c}\text { Jumlah Yg } \\
\text { Ditangkap/trip }\end{array}$} & \multicolumn{4}{|c|}{ Harga (Rp) } \\
\hline & & $\begin{array}{c}0,1- \\
0,2 \mathrm{~kg}\end{array}$ & $\begin{array}{c}0,3-0,4 \\
\mathrm{~kg}\end{array}$ & $\begin{array}{c}0,5-1 \\
\mathrm{Kg}\end{array}$ & $>1 \mathrm{Kg}$ \\
\hline 1 & 82 & 25.000 & 110.000 & 350.000 & 500.000 \\
\hline II & 60 & 25.000 & 100.000 & 300.000 & 400.000 \\
\hline III & 66 & 25.000 & 90.000 & 250.000 & 300.000 \\
\hline Jumlah & 208 & 75.000 & 300.000 & 900.000 & 1.200 .000 \\
\hline $\begin{array}{l}\text { Rata- } \\
\text { rata }\end{array}$ & 69.33 & 25.000 & 110.000 & 350.000 & 500.000 \\
\hline
\end{tabular}

Dari tabel 5 dapat dilihat bahwa jumlah hasil tangkapan nelayan pertrip yang terbesar yaitu ikan jenis II (kerapu lumpur) dan terkecil yaitu jenis I (kerapu sunu), sedangkan harga jual nelayan untuk pedagang pengumpul ikan kerapu mati untuk semua jenis memiliki harga yang sama dimana yang tertinggi pda ukuran $>1 \mathrm{~kg}$ sebesar Rp. 10.000 dan yang terendah yaitu ukuran 0,1-0,2 kg sebesar Rp. 2.000.

Jumlah ikan kerapu hidup yang ditangkap nelayan dan harga jual untuk eksportir berdasarkan jenis tersebut dapat dilihat pada tabel berikut ini :

Tabel 6. Harga jual nelayan untuk konsumen ikan kerapu hidup (Eksportir)

Sumber : Data Primer setelah diolah, 2012

Dari tabel 6 dapat dilihat bahwa jumlah hasil tangkapan nelayan pertrip yang terbesar yaitu yaitu ikan jenis I (kerapu sunu) dan terkecil yaitu jenis II (kerapu lumpur), untuk lebih jelasnya tentang jumlah tangkapan tiap responden nelayan dapat

\begin{tabular}{|c|c|c|c|c|c|}
\hline \multirow{2}{*}{ Jenis } & \multirow{2}{*}{$\begin{array}{c}\text { Jumlah Yg } \\
\text { Ditangkap/trip }\end{array}$} & \multicolumn{4}{|c|}{ Harga (Rp) } \\
\hline & & $\begin{array}{c}0,1-0,2 \\
\mathrm{~kg}\end{array}$ & $\begin{array}{c}0,3-0,4 \\
\mathrm{~kg}\end{array}$ & $0,5-1 \mathrm{Kg}$ & $>1 \mathrm{Kg}$ \\
\hline$I$ & 82 & 22.000 & 55.000 & 180.000 & 360.000 \\
\hline II & 60 & 3.000 & 12.000 & 17.500 & 100.000 \\
\hline III & 66 & 3.000 & 12.000 & 17.500 & 100.000 \\
\hline Jumlah & 208 & 28.000 & 79.000 & 215000 & 560000 \\
\hline $\begin{array}{l}\text { Rata- } \\
\text { rata }\end{array}$ & 69.33 & 9333.33 & 26333.33 & 71666.67 & 186666.67 \\
\hline
\end{tabular}

dilihat pada lampiran 7. Sedangkan harga jual nelayan untuk eksportir yang tertinggi yaitu kerapu sunu yang ukuran $>1 \mathrm{~kg}$ sebesar Rp. 500.000, yang terendah yaitu ukuran 0,1-0,2 kg pada semua jenis ikan kerapu sebesar Rp. 25.000.

Jumlah ikan kerapu mati yang ditangkap nelayan dan harga jual untuk konsumen rumah tangga berdasarkan 
Karina Arfany Arfah "Analisis Potensi Pasar Ikan Kerapu di Pulau Bonetambu Kecamatan Ujung Tanah Kelurahan Barrang Caddi Kota Makassar" jenis tersebut dapat dilihat pada tabel berikut Tabel 8. Potensi Pasar Ikan Kerapu Sunu Hidup ini : Berdasarkan Permintaan Pedagang Pengumpul

Tabel 7. Harga jual nelayan untuk konsumen ikan kerapu segar

\begin{tabular}{c|c|c|c|c|c}
\hline \multirow{2}{*}{ No. } & \multirow{2}{*}{$\begin{array}{c}\text { Jumlah Yg } \\
\text { Ditangkap/trip }\end{array}$} & \multicolumn{4}{|c}{ Harga (Rp) } \\
\cline { 3 - 6 } & & $\mathbf{0 , 1 - 0 , 2}$ & $\mathbf{0 , 3 - 0 , 4}$ & $\mathbf{0 , 5 - 1}$ Kg & $>1$ Kg \\
& & & kg & & \\
\hline I & 24 & 20.000 & 20.000 & 20.000 & 20.000 \\
\hline II & 70 & 15.000 & 15.000 & 15.000 & 15.000 \\
\hline III & 46 & 15.000 & 15.000 & 15.000 & 15.000 \\
\hline Jumlah & $\mathbf{1 4 0}$ & $\mathbf{5 0 . 0 0 0}$ & $\mathbf{5 0 0 0 0}$ & $\mathbf{5 0 . 0 0 0}$ & $\mathbf{5 0 . 0 0 0}$ \\
\hline RATA- & & & & & \\
\hline RATA & $\mathbf{4 6 . 6 7}$ & $\mathbf{1 6 6 6 6 . 6 7}$ & $\mathbf{1 6 6 6 6 . 6 7}$ & $\mathbf{1 6 6 6 6 . 6 7}$ & $\mathbf{1 6 6 6 6 . 6 7}$ \\
\hline
\end{tabular}

Sumber : Data Primer setelah diolah, 2012

Dari tabel 7 dapat dilihat bahwa jumlah hasil tangkapan nelayan pertrip yang terbesar yaitu ikan jenis II (kerapu lumpur) dan terkecil yaitu jenis I (kerapu sunu), Sedangkan harga jual nelayan untuk konsumen rumah tangga yang tertinggi yaitu kerapu sunu semua ukuran sebesar Rp. 20.000, yang terendah yaitu ikan kerapu lumpur dan macan sebesar Rp. 15.000.

Potensi pasar ikan kerapu berdasarkan permintaan pedagang pengumpul dan permintaan eksportir :

\section{Potensi Pasar Berdasarkan Permintaan Pedagang Pengumpul a. Kerapu hidup \\ (1) Kerapu Sunu}

Potensi pasar ikan kerapu sunu hidup berdasarkan dari permintaan pedagang pengumpul di Pulau Bonetambu terlihat pada tabel di bawah ini :

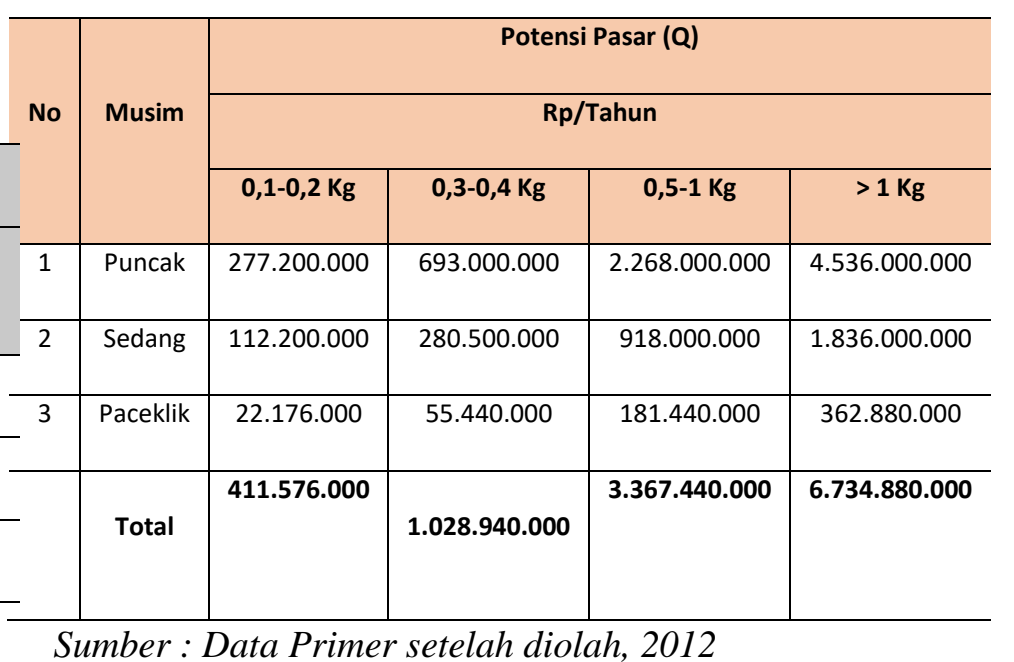

Berdasarkan tabel 8 diketahui bahwa potensi pasar ikan kerapu sunu hidup pada musim puncak yang terbesar adalah ukuran > $1 \mathrm{~kg}$ sebesar Rp. 4.536.000.000 dan yang terkecil adalah ukuran 0,1-0,2 kg sebesar Rp. 277.200.000, untuk musim sedang yang terbesar adalah ukuran $>1 \mathrm{~kg}$ sebesar Rp. 1.836.000.000 dan yang terkecil adalah ukuran 0,1-0,2 kg sebesar Rp. 112.200.000, dan musim paceklik yang terbesar adalah ukuran $>1 \mathrm{~kg}$ sebesar Rp. 362.880 .000 dan yang terkecil adalah ukuran 0,1-0,2 kg sebesar Rp. 22.176.000.

Dilihat dari empat ukuran ikan kerapu tersebut yang memiliki potensi pasar terbesar adalah yang berukuran $>1 \mathrm{~kg}$ dengan total potensi pasar pertahun adalah $\mathrm{Rp}$. 6.734.880.000. Sedangkan total potensi pasar pertripnya adalah Rp. 79.920 .000 dan perbulan Rp. 1.487.160.000. Dari hasil tersebut dapat diketahui bahwa potensi pasar ikan sunu hidup sangat besar.

(2) Kerapu Lumpur

Potensi pasar ikan kerapu lumpur hidup berdasarkan dari permintaan pedagang pengumpul di Pulau Bonetambu terlihat pada tabel di bawah ini :

Tabel 9. Potensi Pasar Ikan Kerapu Lumpur Hidup Berdasarkan Permintaan Pedagang Pengumpul 
Jurnal “Gema Kampus” Edisi Vol.12 No.2 Tahun 2017

\begin{tabular}{|c|c|c|c|c|c|}
\hline \multirow{3}{*}{ No } & \multirow{3}{*}{ Musim } & \multicolumn{4}{|c|}{ Potensi Pasar (Q) } \\
\hline & & \multicolumn{4}{|c|}{ Rp/Tahun } \\
\hline & & $0,1-0,2 \mathrm{Kg}$ & $0,3-0,4 \mathrm{Kg}$ & $0,5-1 \mathrm{Kg}$ & $>1 \mathrm{Kg}$ \\
\hline 1 & Puncak & 29.160 .000 & 116.640 .000 & 170.100 .000 & 972.000 .000 \\
\hline 2 & Sedang & 12.240 .000 & 48.960 .000 & 71.400 .000 & 408.000 .000 \\
\hline \multirow[t]{2}{*}{3} & Paceklik & 2.592 .000 & 10.368 .000 & 15.120 .000 & 86.400 .000 \\
\hline & Total & 43.992 .000 & 175.968 .000 & 256.620 .000 & 1.466 .400 .000 \\
\hline
\end{tabular}

Berdasarkan tabel 9 diketahui bahwa potensi pasar ikan kerapu lumpur hidup pada musim puncak yang terbesar adalah ukuran > $1 \mathrm{~kg}$ sebesar Rp. 972.000.000 dan yang terkecil adalah ukuran 0,1-0,2 kg sebesar Rp. 29.160.000, untuk musim sedang yang terbesar adalah ukuran > $1 \mathrm{~kg}$ sebesar Rp. 408.000.000 dan yang terkecil adalah ukuran 0,1-0,2 kg sebesar Rp. 12.240.000, dan musim paceklik yang terbesar adalah ukuran $>1 \mathrm{~kg}$ sebesar Rp. 86.400 .000 dan yang terkecil adalah ukuran 0,1-0,2 kg sebesar Rp. 2.592.000.

Dilihat dari empat ukuran ikan kerapu tersebut yang memiliki potensi pasar terbesar adalah yang berukuran $>1 \mathrm{~kg}$ dengan total potensi pasar pertahun adalah Rp. 1.466.400.000. Sedangkan total potensi pasar pertripnya adalah Rp. 17.700 .000 dan perbulan Rp. 325.200.000.

(3). Kerapu Macan

Potensi pasar ikan kerapu macan hidup berdasarkan dari permintaan pedagang pengumpul di Pulau Bonetambu terlihat pada tabel di bawah ini :
Tabel 10. Potensi Pasar Ikan Kerapu Macan Hidup Berdasarkan Permintaan Pedagang Pengumpu

\begin{tabular}{c|c|c|c|c}
\hline \multirow{2}{*}{ Musim } & \multicolumn{4}{|c}{ Potensi Pasar (Q) } \\
\cline { 2 - 5 } & \multicolumn{4}{|c}{ Rp/Tahun } \\
\cline { 2 - 5 } & $\mathbf{0 , 1 - 0 , 2 ~ K g}$ & $\mathbf{0 , 3 - 0 , 4 ~ K g}$ & $\mathbf{0 , 5 - 1 ~ K g}$ & $>1 \mathrm{Kg}$ \\
\hline Puncak & 21.600 .000 & 86.400 .000 & 126.000 .000 & 720.000 .000 \\
\hline Sedang & 7.956 .000 & 31.824 .000 & 46.410 .000 & 265.200 .000 \\
\hline Paceklik & 1.728 .000 & 6.912 .000 & 10.080 .000 & 57.600 .000 \\
& & & $\mathbf{1 8 2 . 4 9 0 . 0 0 0}$ & $\mathbf{1 . 0 4 2 . 8 0 0 . 0 0}$ \\
\hline Total & $\mathbf{3 1 . 2 8 4 . 0 0 0}$ & $\mathbf{1 2 5 . 1 3 6 . 0 0 0}$ & & $\mathbf{0}$ \\
& & & & \\
\hline
\end{tabular}

Sumber : Data Primer setelah diolah, 2012

Berdasarkan tabel 10 diketahui bahwa potensi pasar ikan kerapu macan hidup pada musim puncak yang terbesar adalah ukuran > $1 \mathrm{~kg}$ sebesar Rp. 720.000 .000 dan yang terkecil adalah ukuran 0,1-0,2 kg sebesar Rp. 21.600.000, untuk musim sedang yang terbesar adalah ukuran > $1 \mathrm{~kg}$ sebesar Rp. 265.200.000 dan yang terkecil adalah ukuran 0,1-0,2 kg sebesar Rp. 7.956.000, dan musim paceklik yang terbesar adalah ukuran > $1 \mathrm{~kg}$ sebesar Rp. 57.600.000 dan yang terkecil adalah ukuran 0,1-0,2 kg sebesar Rp. 1.728.000.

Dilihat dari empat ukuran ikan kerapu tersebut yang memiliki potensi pasar terbesar adalah yang berukuran $>1 \mathrm{~kg}$ dengan total potensi pasar pertahun adalah $\mathrm{Rp}$. 1.042.800.000. Sedangkan total potensi pasar pertripnya adalah Rp. 12.300 .000 dan perbulan Rp. 229.500.000. Dari hasil tersebut dapat diketahui bahwa semakin besar ukuran (size) dari ikan kerapu berarti semakin tinggi nilai jualnya.

\section{b. Kerapu Mati}

(1). Kerapu Sunu

Potensi pasar ikan kerapu sunu mati berdasarkan dari permintaan pedagang pengumpul di Pulau Bonetambu terlihat pada tabel di bawah ini : 
Karina Arfany Arfah "Analisis Potensi Pasar Ikan Kerapu di Pulau Bonetambu Kecamatan Ujung Tanah Kelurahan Barrang Caddi Kota Makassar"

Tabel 11. Potensi Pasar Ikan Kerapu Sunu Mati Berdasarkan Permintaan Pedagang Pengumpul

\begin{tabular}{|c|c|c|c|c|c|c|c|c|c|c|}
\hline \multicolumn{6}{|c|}{ No } & \multirow[t]{2}{*}{ Musim } & \multicolumn{4}{|c|}{ Rp/Tahun } \\
\hline \multirow{3}{*}{ No } & \multirow{3}{*}{ Musim } & \multicolumn{4}{|c|}{ Potensi Pasar (Q) } & & $0,1-0,2 \mathrm{Kg}$ & $0,3-0,4 \mathrm{Kg}$ & $0,5-1 \mathrm{Kg}$ & $>1 \mathrm{Kg}$ \\
\hline & & \multicolumn{4}{|c|}{ Rp/Tahun } & Puncak & 23.040 .000 & 46.080 .000 & 69.120 .000 & 115.200 .000 \\
\hline & & $0,1-0,2 \mathrm{Kg}$ & $0,3-0,4 \mathrm{Kg}$ & $0,5-1 \mathrm{Kg}$ & $>1 \mathrm{Kg}-\frac{2}{2}$ & Sedang & 8.976 .000 & 17.952 .000 & 26.928 .000 & 44.880 .000 \\
\hline 1 & Puncak & 12.000 .000 & 24.000 .000 & 36.000 .000 & $60.000 .000 \frac{1}{3}$ & Paceklik & 1.728 .000 & 3.456 .000 & 5.184 .000 & 8.640 .000 \\
\hline 2 & Sedang & 5.440 .000 & 10.880 .000 & 16.320 .000 & 27.200 .000 & Total & 33.744 .000 & 67.488 .000 & 101.232.000 & 168.720 .000 \\
\hline \multirow[t]{2}{*}{3} & Paceklik & 768.000 & 1.536 .000 & 2.304 .000 & \multicolumn{6}{|c|}{${ }^{3.840 .000}$ Sumber : Data Primer setelah diolah, 2012} \\
\hline & Total & 18.208 .000 & 36.416 .000 & 54.624 .000 & 91.040 .000 & & dasark & tabel & dike & \\
\hline
\end{tabular}

Sumber : Data Primer setelah diolah, 2012

Berdasarkan tabel 11 diketahui bahwa potensi pasar ikan kerapu sunu mati pada musim puncak yang terbesar adalah ukuran > $1 \mathrm{~kg}$ sebesar Rp. 60.000 .000 dan yang terkecil adalah ukuran 0,1-0,2 kg sebesar Rp. 12.000.000, untuk musim sedang yang terbesar adalah ukuran $>1 \mathrm{~kg}$ sebesar Rp. 27.200.000 dan yang terkecil adalah ukuran 0,1-0,2 kg sebesar Rp. 5.440.000, dan musim paceklik yang terbesar adalah ukuran $>1 \mathrm{~kg}$ sebesar Rp. 3.840 .000 dan yang terkecil adalah ukuran $0,1-0,2 \mathrm{~kg}$ sebesar Rp. 768.000.

Dilihat dari empat ukuran ikan kerapu tersebut yang memiliki potensi pasar terbesar adalah yang berukuran $>1 \mathrm{~kg}$ dengan total potensi pasar pertahun adalah Rp. 91.040.000. Sedangkan total potensi pasar pertripnya adalah Rp. 1.060 .000 dan perbulan Rp. 20.080.000.

\section{(2). Kerapu Lumpur}

Potensi pasar ikan kerapu lumpur mati berdasarkan dari permintaan pedagang pengumpul di Pulau Bonetambu terlihat pada tabel di bawah ini :

Tabel 12. Potensi Pasar Ikan Kerapu Lumpur Mati Berdasarkan Permintaan Pedagang Pengumpul bahwa potensi pasar ikan kerapu lumpur mati pada musim puncak yang terbesar adalah ukuran > $1 \mathrm{~kg}$ sebesar Rp. 115.200.000 dan yang terkecil adalah ukuran 0,1-0,2 kg sebesar Rp. 2.3040.000, untuk musim sedang yang terbesar adalah ukuran > $1 \mathrm{~kg}$ sebesar Rp. 44.880 .000 dan yang terkecil adalah ukuran 0,1-0,2 kg sebesar Rp. 8.976.000, dan musim paceklik yang terbesar adalah ukuran > $1 \mathrm{~kg}$ sebesar Rp. 8.640.000 dan yang terkecil adalah ukuran 0,1-0,2 kg sebesar Rp. 1.728.000.

Dilihat dari empat ukuran ikan kerapu tersebut yang memiliki potensi pasar terbesar adalah yang berukuran $>1 \mathrm{~kg}$ dengan total potensi pasar pertahun adalah $\mathrm{Rp}$. 168.720.000. Sedangkan total potensi pasar pertripnya adalah Rp. 1.980 .000 dan perbulan Rp. 37.140.000.

\section{(3). Kerapu Macan}

Potensi pasar ikan kerapu macan mati berdasarkan dari permintaan pedagang pengumpul di Pulau Bonetambu terlihat pada tabel di bawah ini :

Tabel 13. Potensi Pasar Ikan Kerapu Macan Mati Berdasarkan Permintaan Pedagang Pengumpul

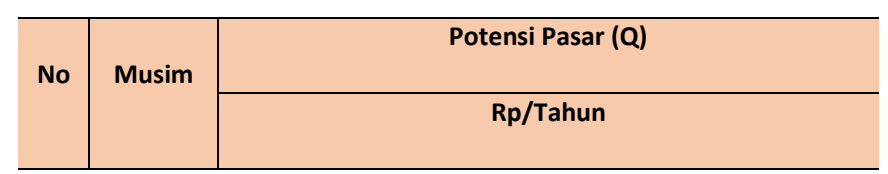


Jurnal "Gema Kampus" Edisi Vol.12 No.2 Tahun 2017

\begin{tabular}{|c|c|c|c|c|c|}
\hline & & $0,1-0,2 \mathrm{Kg}$ & $0,3-0,4 \mathrm{Kg}$ & $0,5-1 \mathrm{Kg}$ & >1 Kg Berdasarkan tabel 14 diketahui bahwa \\
\hline 1 & Puncak & 13.440 .000 & 26.880 .000 & 40.320 .000 & $\begin{array}{l}\text { 6.7200.00Botensi pasar ikan kerapu sunu hidup pada } \\
\text { musim puncak yang terbesar adalah ukuran }>\end{array}$ \\
\hline 2 & Sedang & 4.896 .000 & 9.792 .000 & 14.688 .000 & ebesar Rp. 13.200.000.000 dan yang \\
\hline \multirow[t]{2}{*}{3} & Paceklik & 864.000 & 1.728 .000 & 2.592 .000 & 4.320.00qerkecil adalah ukuran $0,1-0,2 \mathrm{~kg}$ sebesar \\
\hline & Total & 19.200 .000 & 38.400 .000 & 57.60 & $\begin{array}{r}\mathbf{9 6 . 0 0 0 . 0 0 0} 60.000 .000 \\
\text { terbesar adala }\end{array}$ \\
\hline
\end{tabular}

Sumber : Data Primer setelah diolah, 2012

Berdasarkan tabel 13 diketahui bahwa potensi pasar ikan kerapu macan mati pada musim puncak yang terbesar adalah ukuran $>1$ $\mathrm{kg}$ sebesar Rp. 67.200.000 dan yang terkecil adalah ukuran 0,1-0,2 kg sebesar Rp. 13.440.000, untuk musim sedang yang terbesar adalah ukuran $>1 \mathrm{~kg}$ sebesar Rp. 24.480 .000 dan yang terkecil adalah ukuran 0,1-0,2 kg sebesar Rp. 4.896.000, dan musim paceklik yang terbesar adalah ukuran $>1 \mathrm{~kg}$ sebesar Rp. 4.320 .000 dan yang terkecil adalah ukuran 0,1-0,2 kg sebesar Rp. 864.000.

Dilihat dari empat ukuran ikan kerapu tersebut yang memiliki potensi pasar terbesar adalah yang berukuran $>1 \mathrm{~kg}$ dengan total potensi pasar pertahun adalah Rp. 96.000.000. Sedangkan total potensi pasar pertripnya adalah Rp. 1.100.000 dan perbulan Rp. 21.000.000.

\section{Potensi Pasar Berdasarkan Permintaan Eksportir}

(a). Kerapu Sunu Hidup

Potensi pasar ikan kerapu sunu hidu berdasarkan dari permintaan eksportir terlih: pada tabel di bawah ini :

Tabel 14. Potensi Pasar Ikan Kerapu Sunu Hidu Berdasarkan Permintaan Eksportir

\begin{tabular}{|c|c|c|c|}
\hline \multirow{3}{*}{ Musim } & \multicolumn{3}{|c|}{ Potensi Pasar (Q) } \\
\hline & \multicolumn{3}{|c|}{ Rp/Tahun } \\
\hline & $0,1-0,2 \mathrm{Kg}$ & $0,3-0,4 \mathrm{Kg}$ & $0,5-1 \mathrm{Kg}$ \\
\hline Puncak & 660.000 .000 & 2.904 .000 .000 & 9.240 .000 .000 \\
\hline Sedang & 289.000 .000 & 1.271 .600 .000 & 4.046 .000 .000 \\
\hline Paceklik & 66.000 .000 & 290.400 .000 & 924.000 .000 \\
\hline Total & 1.015 .000 .000 & 4.466 .000 .000 & 14.210.000.000 \\
\hline
\end{tabular}

Sumber : Data Primer setelah diolah, 2012
5.780.000.000 dan yang terkecil adalah ukuran 0,1-0,2 kg sebesar Rp. 289.000.000, dan musim paceklik yang terbesar adalah ukuran > 1 kg sebesar Rp. 1.320.000.000 dan yang terkecil adalah ukuran 0,1-0,2 $\mathrm{kg}$ sebesar Rp. 66.000.000.

Dilihat dari empat ukuran ikan kerapu tersebut yang memiliki potensi pasar terbesar adalah yang berukuran $>1 \mathrm{~kg}$ dengan total potensi pasar pertahun adalah Rp. 20.300.000.000. Sedangkan total potensi pasar pertripnya adalah Rp. 250.000.000 dan perbulan Rp. 4.525.000.000.

\section{(b). Kerapu Lumpur Hidup}

Potensi pasar ikan kerapu lumpur hidup berdasarkan dari permintaan eksportir terlihat pada tabel di bawah ini :

Tabel 15 Potensi Pasar Ikan Kerapu Lumpur Hidup Berdasarkan Permintaan Eksportir

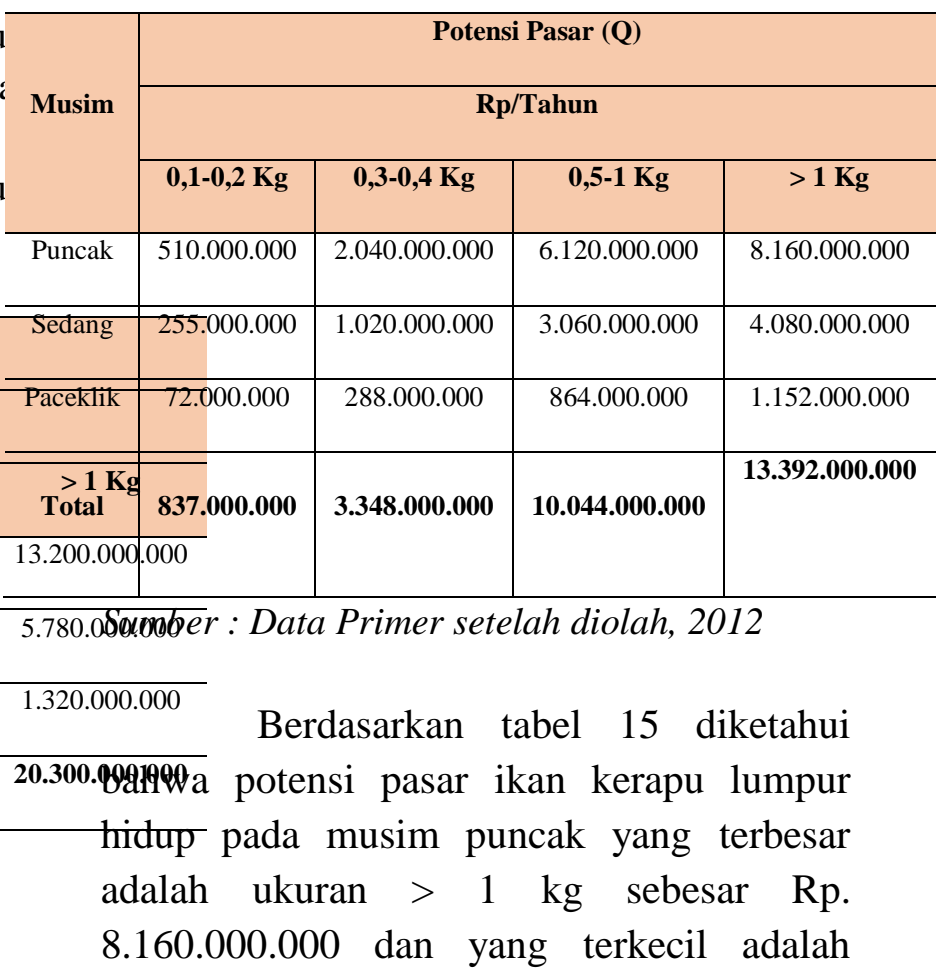


ukuran 0,1-0,2 kg sebesar Rp. 510.000.000, untuk musim sedang yang terbesar adalah ukuran > $1 \mathrm{~kg}$ sebesar Rp. 4.080.000.000 dan yang terkecil adalah ukuran $0,1-0,2 \mathrm{~kg}$ sebesar Rp. 255.000.000, dan musim paceklik yang terbesar adalah ukuran $>1 \mathrm{~kg}$ sebesar Rp. 1.152.000.000 dan yang terkecil adalah ukuran 0,1-0,2 $\mathrm{kg}$ sebesar Rp. 72.000.000.

Dilihat dari empat ukuran ikan kerapu tersebut yang memiliki potensi pasar terbesar adalah yang berukuran $>1 \mathrm{~kg}$ dengan total potensi pasar pertahun adalah $\mathrm{Rp}$. 13.392.000.000. Sedangkan total potensi pasar pertripnya adalah Rp. 176.000.000 dan perbulan Rp. 3.036.000.000.

(c). Kerapu Macan Hidup

Potensi pasar ikan kerapu macan hidup berdasarkan dari permintaan eksportir terlihat pada tabel di bawah ini :

Tabel 16. Potensi Pasar Ikan Kerapu Macan Hidup Berdasarkan Permintaan Eksportir yang terkecil adalah ukuran 0,1-0,2 kg sebesar Rp. 221.000.000, dan musim paceklik yang terbesar adalah ukuran $>1 \mathrm{~kg}$ sebesar Rp. 792.000.000 dan yang terkecil adalah ukuran 0,1-0,2 kg sebesar Rp. 66.000.000.

Dilihat dari empat ukuran ikan kerapu tersebut yang memiliki potensi pasar terbesar adalah yang berukuran $>1 \mathrm{~kg}$ dengan total potensi pasar pertahun adalah $\mathrm{Rp}$. 10.284.000.000. Sedangkan total potensi pasar pertripnya adalah Rp. 129.000.000 dan perbulan Rp. 2.295.000.000.

\section{Potensi Pasar Berdasarkan Permintaan Konsumen Rumah Tangga}

(a). Kerapu Sunu Mati

Potensi pasar ikan kerapu sunu mati (segar) berdasarkan dari permintaan konsumen terlihat pada tabel di bawah ini :

Tabel 17. Potensi Pasar Ikan Kerapu Sunu Segar Berdasarkan Permintaan Konsumen Rumah Tangga

\begin{tabular}{|c|c|c|c|c|c|c|c|c|c|}
\hline \multirow{3}{*}{ Musim } & \multicolumn{4}{|c|}{ Potensi Pasar (Q) } & \multirow{3}{*}{ Musim } & \multicolumn{4}{|c|}{ Potensi Pasar (Q) } \\
\hline & \multicolumn{3}{|c|}{ Rp/Tahun } & \multirow[t]{2}{*}{ No } & & \multicolumn{4}{|c|}{ Rp/Tahun } \\
\hline & $0,1-0,2 \mathrm{Kg}$ & $0,3-0,4 \mathrm{Kg}$ & $0,5-1 \mathrm{Kg}$ & & & $0,1-0,2 \mathrm{Kg}$ & 0,3-0,4 Kg & $0,5-1 \mathrm{Kg}$ & $>1 \mathrm{Kg}$ \\
\hline Puncak & 570.000 .000 & 2.052 .000 .000 & 5.700 .000 .000 & 6.840 .000 & OPRuncak & 33.120 .000 & 55.200 .000 & 77.280 .000 & 220.800 .000 \\
\hline Sedang & 221.000 .000 & 795.600 .000 & 2.210 .000 .000 & 2.652 .000 & Ossedang & 14.076 .000 & 23.460 .000 & 32.844 .000 & 93.840 .000 \\
\hline Paceklik & 66.000 .000 & 237.600 .000 & 660.000 .000 & $792.0 B 00$. & pOPaceklik & 3.312 .000 & 5.520 .000 & 7.728 .000 & $22.080 . .000$ \\
\hline Total & 857.000 .000 & 3.085 .200 .000 & 8.570 .000 .000 & 10.284 .00 & .00Dotal & $\begin{array}{l}\mathbf{5 0 . 5 0 8 . 0 0 0} \\
\end{array}$ & 84.180 .000 & 117.852 .000 & 336.720 .000 \\
\hline
\end{tabular}

Sumber : Data Primer setelah diolah, 2012

Sumber : Data Primer setelah diolah, 2012

Berdasarkan tabel 17 diketahui

Berdasarkan tabel 16 diketahui bahwa potensi pasar ikan kerapu macan hidup pada musim puncak yang terbesar adalah ukuran > $1 \mathrm{~kg}$ sebesar Rp. 6.840.000.000 dan yang terkecil adalah ukuran 0,1-0,2 kg sebesar Rp. 570.000.000, untuk musim sedang yang terbesar adalah ukuran > 1 kg sebesar Rp. 2.652.000.000 dan bahwa potensi pasar ikan kerapu sunu segar pada musim puncak yang terbesar adalah ukuran > $1 \mathrm{~kg}$ sebesar Rp. 220.800.000 dan yang terkecil adalah ukuran 0,1-0,2 $\mathrm{kg}$ sebesar Rp. 33.120.000, untuk musim sedang yang terbesar adalah ukuran $>1 \mathrm{~kg}$ sebesar Rp. 93.840.000 dan yang terkecil adalah ukuran 0,1-0,2 kg sebesar Rp. 14.076.000, 
Jurnal "Gema Kampus" Edisi Vol.12 No.2 Tahun 2017 dan musim paceklik yang terbesar adalah ukuran > $1 \mathrm{~kg}$ sebesar Rp. 22.080 .000 dan yang terkecil adalah ukuran 0,1-0,2 kg sebesar Rp. 3.312.000.

Dilihat dari empat ukuran ikan kerapu tersebut yang memiliki potensi pasar terbesar adalah yang berukuran $>1 \mathrm{~kg}$ dengan total potensi pasar pertahun adalah Rp. 336.720.000. Sedangkan total potensi pasar pertripnya adalah Rp. 4.140 .000 dan perbulan Rp. 74.980.000.

(b). Kerapu Lumpur Mati

Potensi pasar ikan kerapu lumpur mati (segar) berdasarkan dari permintaan

Dilihat dari empat ukuran ikan kerapu tersebut yang memiliki potensi pasar terbesar adalah yang berukuran $>1 \mathrm{~kg}$ dengan total potensi pasar pertahun adalah Rp. 252.540.000. Sedangkan total potensi pasar pertripnya adalah Rp. 3.105 .000 dan perbulan Rp. 56.235.000.

\section{(c). Kerapu Macan Mati}

Potensi pasar ikan kerapu macan mati (segar) berdasarkan dari permintaan konsumen terlihat pada tabel di bawah ini :

Tabel 19. Potensi Pasar Ikan Kerapu Macan Segar Berdasarkan Permintaan Konsumen Rumah Tangga

konsumen terlihat pada tabel di bawah ini :

Tabel 18. Potensi Pasar Ikan Kerapu Lumpur Segar Berdasarkan Permintaan Konsumen Rumah Tangga

\begin{tabular}{|c|c|c|c|c|c|}
\hline \multirow{3}{*}{ No } & \multirow{3}{*}{ Musim } & \multicolumn{4}{|c|}{ Potensi Pasar (Q) } \\
\hline & & \multicolumn{4}{|c|}{ Rp/Tahun } \\
\hline & & $0,1-0,2 \mathrm{Kg}$ & $0,3-0,4 \mathrm{Kg}$ & $0,5-1 \mathrm{Kg}$ & $>1$ \\
\hline 1 & Puncak & 33.120 .000 & 55.200 .000 & 77.280 .000 & 165.6 \\
\hline 2 & Sedang & 14.076 .000 & 23.460 .000 & 32.844 .000 & 70.380 . \\
\hline 3 & Paceklik & 3.312 .000 & 5.520 .000 & 7.728 .000 & 16.560 . \\
\hline & Total & 50.508.000 & 84.180 .000 & 117.852 .000 & 252.5 \\
\hline
\end{tabular}

Sumber : Data Primer setelah diolah, 2012

Berdasarkan tabel 18 diketahui bahwa potensi pasar ikan kerapu lumpur hidup pada musim puncak yang terbesar adalah ukuran > $1 \mathrm{~kg}$ sebesar Rp. 165.600.000 dan yang terkecil adalah ukuran 0,1-0,2 kg sebesar Rp. 3.3120.000, untuk musim sedang yang terbesar adalah ukuran > $1 \mathrm{~kg}$ sebesar Rp. 70.380.000 dan yang terkecil adalah ukuran 0,1-0,2 kg sebesar Rp. 14.076.000, dan musim paceklik yang terbesar adalah ukuran $>1 \mathrm{~kg}$ sebesar Rp. 16.560.000 dan yang terkecil adalah ukuran 0,1-0,2 kg sebesar Rp. 3.312.000.

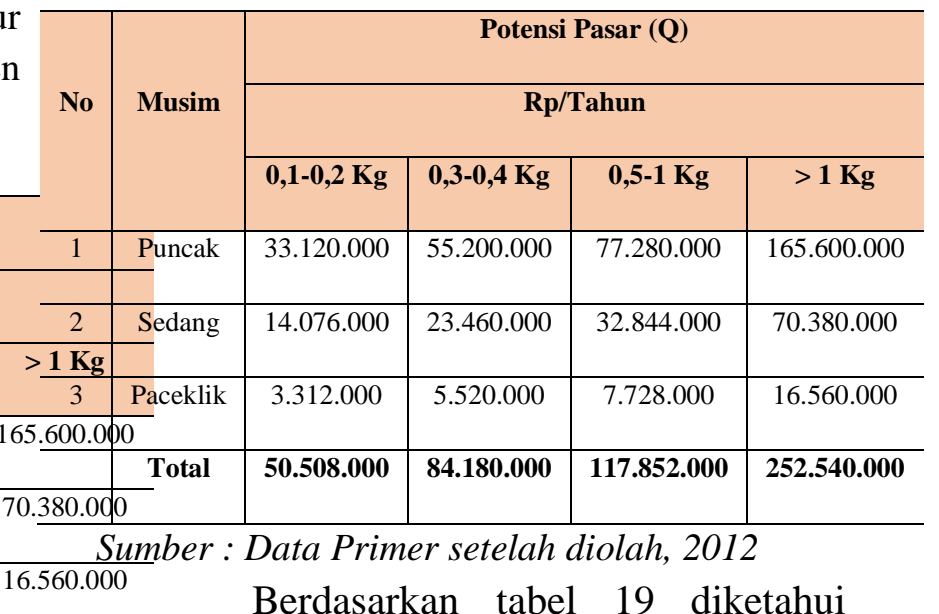

Berdasarkan tabel 19 diketahui hidup pada musim puncak yang terbesar adalah ukuran $>1 \mathrm{~kg}$ sebesar Rp. 165.600.000 dan yang terkecil adalah ukuran 0,1-0,2 kg sebesar Rp. 33.120.000, untuk musim sedang yang terbesar adalah ukuran > $1 \mathrm{~kg}$ sebesar Rp. 70.380 .000 dan yang terkecil adalah ukuran 0,1-0,2 kg sebesar Rp. 14.076.000, dan musim paceklik yang terbesar adalah ukuran $>1 \mathrm{~kg}$ sebesar Rp. 16.560.000 dan yang terkecil adalah ukuran 0,1-0,2 kg sebesar Rp. 3.312.000.

Dilihat dari empat ukuran ikan kerapu tersebut yang memiliki potensi pasar terbesar adalah yang berukuran $>1 \mathrm{~kg}$ dengan total potensi pasar pertahun adalah $\mathrm{Rp}$. 252.540.000. Sedangkan total potensi pasar 

Kelurahan Barrang Caddi Kota Makassar"

pertripnya adalah Rp. 3.105 .000 dan perbulan Rp. 56.235.000.

\section{Kesimpulan Dan Saran}

\section{A. Kesimpulan}

Dari hasil penelitian di Pulau Bonetambu dapat ditarik kesimpulan berdasarkan permintaan konsumen, pedagang pengumpul dan eksportir ikan kerapu memiliki potensi pasar yang besar. Dari tiga komoditas ikan kerapu (Sunu, Lumpur dan Macan) ukuran $>1 \mathrm{~kg}$ yang memiliki potensi pasar yang besar. Untuk kerapu hidup yang memiliki potensi pasar terbesar adalah kerapu sunu (Plectopormus leopardus), sedangkan untuk kerapu mati yang memiliki potensi pasar yang besar adalah kerapu lumpur (Epinephelus coloides).

\section{B. Saran}

Saran yang dapat diberikan adalah sebagai berikut :

1. Sebaiknya pemerintah perlu melakukan penyuluhan tentang alat tangkap yang lebih modern sehingga hasil tangkapan nelayan meningkat dan dapat meningkatkan pangsa pasar.

2. Sebaiknya nelayan tidak hanya menangkap ikan kerapu tetapi juga membudidayakannya.

\section{DAFTAR PUSTAKA}

Amir M, Taufiq. 2005. Dinamika Pemasaran. PT Raja Grafindo Persada. Jakarta.

Amir. M. S. 2000. Strategi Pemasaran Ekspor. PT. Pustaka Binawan Pressindo. Jakarta.

Boone dan Kurtz.1987. Peluang Pasar dan Potensi Pasar.(www.shvoong.com).

Gudtinan, J dan Gordon, W.P. 1997.Strategi Program Manajemen

Pemasaran.Erlangga. Jakarta.

Hanafiah, A. M, dan Saefuddin, A. M. 2006.

Tata Niaga Hasil Perikanan. UIPress.Jakarta.

Hutaruk, Alfred. 1996. Sistem Pelaksanaan Ekspor, Impor dan Lalu Lintas Devisa. Erlangga. Jakarta.

Kotler, Philip. 1999. Dasar-dasar

Pemasaran. Pren Halindo. Jakarta. .2001. Manajemen Pemasaran. Edisi Bahasa Indonesia. Terjemahan Hendar dkk. Erlangga. Jakarta.

Malthus. 1798. Teori Kependudukan. http://christdawie.blogspot.com/2011/0 7.

Monintja, D.R dan M. Badrudin. 1996. Ketentuan pelaksanaan perikanan yang bertanggung jawab (Code of conduct for responsible fisheries) .Marine Resources Evolution and Planning (MREP), Marine and Coastal Ecological System and Processes (MCESP) . Pusat Penelitian dan Pengembangan Perikanan. 
Jurnal "Gema Kampus" Edisi Vol.12 No.2 Tahun 2017

Murtidjo, A. 2002.Budidaya Kerapu

Dalam Tambak. Penerbit Kaniskus.

Jakarta.

Prasetiyo, Bambang dan Lina Miftahul Jannah.2005. Metode Penelitian

Kuantitatif Teori dan Aplikasinya.

PT. Grafindo Persada. Jakarta.

Slamet, dkk.2001. Pengamatan Aspek

Biologi Reproduksi eberapa Jenis

Ikan Kerapu.Teknologi Budidaya Laut

dan Pengembangan Sea Farming di Indonesia.DKP Kerjasama JICA.

Stanton. J. 2003. Prinsip Pemasaran. Edisi ke-7.Erlangga. Jakarta.

Tan dan Tan, 1972. Biology of Mudgrouper,

Epinepheli sta uvina.

Zikmund dan D'Amico MOA. 2007.

Identifikasi dan Peluang Pasar.

(www.kopkarisejahtera.wordpress

.com). 